\title{
Acta
Biochimica
Polonica
}

Vol. 48 No. 3/2001

$729-737$

QUARTERLY

We dedicate this work to the memory of Professor Jacek Augustyniak

\section{Effect of growth at low temperature on the alternative pathway respiration in Acanthamoeba castellanii mitochondria}

\author{
Wiesława Jarmuszkiewicz ${ }^{\natural}$, Olaf Frączyk and Lilla Hryniewiecka \\ Department of Bioenergetics, Institute of Molecular Biology and Biotechnology, \\ Adam Mickiewicz University, Poznań, Poland
}

Received: 22 January, 2001; revised: 25 April, 2001; accepted: 19 June, 2001

Key words: mitochondria, alternative oxidase, low temperature adaptation, Acanthamoeba castellanii

Mitochondria of amoeba Acanthamoeba castellanii in addition to the conventional cytochrome pathway possess, like plant mitochondria, a cyanide-resistant alternative quinol oxidase. In mitochondria isolated from amoeba batch culture grown temporarily at low temperature $\left(6^{\circ} \mathrm{C}\right)$, higher respiration was accompanied by lower coupling parameters as compared to control culture (grown at $28^{\circ} \mathrm{C}$ ). In the presence of benzohydroxamate, respiratory rates and coupling parameters were similar in both types of mitochondria indicating that growth in cold conditions did not disturb the cytochrome pathway. Increased contribution of alternative oxidase in total mitochondrial respiration in low-temperature-grown amoeba cells was confirmed by calculation of its contribution using ADP/O measurements. Furthermore, in mitochondria from low-temperature- grown cells the content of the alternative oxidase was increased and correlated with the increase in the unstimulated and GMP-stimulated cyanide-resistant respiratory activity. A possible physiological role of higher activity of alternative oxidase as response to growth at a low temperature in unicellular organisms, such as amoeba, is discussed.

This research was supported by the State Committee of Scientific Research (KBN, Poland) grant No. 6 P04A 00518.

${ }^{\square}$ To whom correspondence should be addressed: Wiesława Jarmuszkiewicz, Department of Bioenergetics, Institute of Molecular Biology and Biotechnology, Adam Mickiewicz University, A. Fredry 10, 61-701 Poznań, Poland; phone: (48 61) 829 4531; fax: (48 61) 829 4503;

e-mail: wiesiaj@main.amu.edu.pl

Abbreviations: AOX, alternative oxidase; BHAM, benzohydroxamate; LTG cultures, low-temperature-grown cultures; state 3, phosphorylating state in the presence of ADP; state 4, respiration in the absence of $\mathrm{ADP}$; $\mathrm{RC}$, respiratory control ratio; $\Delta \Psi$, mitochondrial transmembrane electrical potential. 
The mitochondrial respiratory chain of the amoeba Acanthamoeba castellanii, like that of plant mitochondria, possesses both cyanideand antimycin-resistant alternative oxidase (AOX) and the conventional cytochrome $c$ oxidase [1, 2]. Furthermore, A. castellanii, a non-photosynthetic amoeboid protozoon, and higher plants share other common features at the level of respiratory chain of the inner mitochondrial membrane, like the presence of the non-phosphorylating rotenone-insensitive internal (matricial face) and external (cytosolic face) NADH dehydrogenases [1, 3].

As in higher plant mitochondria, the alternative pathway of amoeba mitochondria branches from the main respiratory chain at the level of ubiquinone, and electron flux through alternative oxidase is not coupled to ADP phosphorylation. While in plant mitochondria the activity of AOX is stimulated by $\alpha$-keto acids and regulated by the redox state of intermolecular disulfide bond (the reduced state is more active) [4-7], these regulations do not concern AOX in amoeba mitochondria [8]. The amoeba cyanide-resistant AOX is strongly stimulated by purine nucleoside $5 '$-monophosphates AMP, GMP (the lowest $K_{\mathrm{m}}$ of stimulation) and IMP [1, 9]. A similar effect of purine mononucleotides on the cyanide-resistant alternative pathway was observed in other microorganisms: Euglena gracilis [10], Monilella tomentosa [11], Neurospora crassa [12], Paramecium tetraurelia [13], and Hansenula anomala [14]. Despite important differences between plant and amoeba AOX at the level of regulation, monoclonal antibodies developed against Suaromatum guttatum cross-react with the AOX protein of A. castellanii mitochondria [8], as they do with proteins of wide range of thermogenic and non-thermogenic plant species, some fungi, and trypanosomes [4-7, 15]. This indicates that the AOX protein is well conserved throughout various species.

The only obvious physiological function of the cyanide-resistant alternative pathway has been recognized in specialized plant thermo- genic tissues (spadices of Araceae) to consist in heat generation related to reproductive processes [16]. In non-thermogenic plant tissues and unicellular organisms, the physiological role of this energy-dissipating pathway remains unclear. AOX could play a central role in the maintaining of cell energy metabolism balance related to regulation of ATP production, control of the $\mathrm{NADH} / \mathrm{NAD}^{+}$ratio, and limitation of the production of mitochondrial reactive oxygen species [6, 7, 17-22].

Mitochondrial respiration rates are affected by numerous factors, including growth temperature. Most, if not all, studies on the effect of growth temperature on the mitochondrial respiration, especially on the activity of the alternative respiratory pathway, concerned higher plants. The increased rates of respiration observed in plants grown at low temperature were attributed to a greater participation of the alternative pathway [17]. Growth of plants at low temperatures often results in higher cyanide-resistant respiratory activity [23] which could be correlated with increased synthesis of AOX protein [24, 25] or aox gene mRNA [26]. Increased activity of the alternative pathway as a response to low temperature may prevent the formation of toxic active oxygen species that can originate from ubiquinone overreduction accompanying inhibition of the cytochrome pathway [17, 19]. However, this adaptation to temperature is not a general feature of plants [27, 28].

The aim of this study was to determine the effect of low temperature of growth on the amoeba mitochondrial respiration and AOX activity and protein content.

\section{MATERIALS AND METHODS}

Cell culture and isolation of mitochondria. Soil amoeba $A$. castellanii, strain Neff, was cultured for $72 \mathrm{~h}$ as described by Jarmuszkiewicz et al. [8]. Control amoeba batch culture was routinely grown at $28^{\circ} \mathrm{C}$. From batch cultures grown at $28^{\circ} \mathrm{C}$ for $12 \mathrm{~h}$ amoeba 
cells were transferred to $6^{\circ} \mathrm{C}$ for $24 \mathrm{~h}$ (lowtemperature-grown cultures, LTG) and then placed again at $28^{\circ} \mathrm{C}$ for $12 \mathrm{~h}$ (Fig. 1). To isolate mitochondria, trophozoites of amoeba were from $48 \mathrm{~h}$ cultures when both control and LTG cells reached a similar density, i.e. $6-7 \times 10^{6}$ cells $/ \mathrm{ml}$. Mitochondria were isolated as described before [8].

Oxygen uptake and membrane potential. Oxygen uptake was measured polarographically with a Rank Brothers (Cambridge, U.K.) oxygen electrode in $3 \mathrm{ml}$ of the medium $\left(25^{\circ} \mathrm{C}\right)$ consisting of $120 \mathrm{mM} \mathrm{KCl}, 10 \mathrm{mM}$ Tris/Cl, pH 7.4, $3 \mathrm{mM} \mathrm{KH}{ }_{2} \mathrm{PO}_{4}, 8 \mathrm{mM} \mathrm{MgCl}_{2}$, and $0.2 \%$ bovine serum albumin (BSA), and 1-2 $\mathrm{mg}$ of mitochondrial protein. The measurement temperature was $25^{\circ} \mathrm{C}$ both for control and LTG mitochondrial preparations. The membrane potential $(\Delta \Psi)$ of mitochondria was measured simultaneously with oxygen uptake using a tetraphenylphosphonium-specific electrode according to Kamo et al. [29]. For calculation of $\Delta \Psi$ value, the matrix volume of amoeba mitochondria was assumed as $2.0 \mu \mathrm{l} /$ $\mu \mathrm{g}$ protein. Succinate $(10 \mathrm{mM})$ in the presence of rotenone $(15 \mu \mathrm{M})$ was used as respiratory substrate. Cyanide (1.5 mM) and benzohydroxamate (BHAM, $1.5 \mathrm{mM}$ ) were used as inhibitors of the cytochrome pathway and of the alternative oxidase, respectively. To fully activate alternative oxidase, $0.8 \mathrm{mM}$ GMP was added to the incubation medium. Values of $\mathrm{O}_{2}$ uptake and $\Delta \Psi$ are expressed in nmol $\mathrm{O} \times$ $\min ^{-1}$ per $\mathrm{mg}$ protein and $\mathrm{mV}$, respectively.

Protein was estimated by the biuret method [30] with BSA fraction V as a standard.

SDS/PAGE and immunoblotting. Up to 80 $\mu \mathrm{g}$ of freshly isolated mitochondrial protein was solubilized in the sample buffer $(1 \%(\mathrm{w} / \mathrm{v})$ SDS, $60 \mathrm{mM}$ Tris/Cl (pH 6.8), 10\% glycerol, $0.004 \%(\mathrm{w} / \mathrm{v})$ bromophenol blue, and $8 \%$ mercaptoethanol) and boiled for 4 min. Mitochondrial samples were subjected to SDS/PAGE (12.5\% non-urea gel), followed by Western blotting [8]. Bio-Rad prestained low molecular mass markers were used. Antibodies against alternative oxidase proteins of $S$. guttatum (generously supplied by Dr. T.E. Elthon) were used at dilutions of 1:1000. Alternative oxidase bands were visualized using the Amersham ECL system.

\section{RESULTS}

Effect of low temperature on growth of $A$. castellanii in batch culture

As shown previously, in amoeba $A$. castellanii, mitochondrial respiratory activities including the cyanide-resistant respiration change with the age of amoeba batch culture revealing a maximum at the exponential phase of growth [8]. Changes in membrane fatty acid composition during growth of amoeba in batch culture were also observed [31]. Therefore, to isolate mitochondria, amoeba trophozoites were harvested $48 \mathrm{~h}$ after inoculation when both, control and cold-exposed, cultures reached the early stationary phase of growth $\left(6-7 \times 10^{6}\right.$ cells $\left./ \mathrm{ml}\right)$ (Fig. 1).

Respiratory characteristics of mitochondria isolated from amoeba cells grown at various temperatures

Respiratory rates (measured at $25^{\circ} \mathrm{C}$ ), both in state 3 and state 4 , in the absence of BHAM (an inhibitor of AOX), were significantly higher in mitochondria isolated from low-temperature-grown cells than in mitochondria from control high-temperature-grown cells (Fig. 2). The increase in respiration of mitochondria from cells grown at low temperature was accompanied by a decrease in respiratory control ratio (RC) and $\mathrm{ADP} / \mathrm{O}$ values, indicating lowering of mitochondrial coupling. In the absence of BHAM, in mitochondria isolated from low-temperature-grown cells $\mathrm{ADP} / \mathrm{O}$ was $0.85 \pm 0.15$ (S.D., $\mathrm{n}=8$, for four different mitochondrial preparations) and $\mathrm{RC}$ was $1.3 \pm 0.2$ (S.D., $\mathrm{n}=8$ ), while in control mitochondria $\mathrm{ADP} / 0$ was $1.18 \pm 0.10$ (S.D., $\mathrm{n}=6$, for three 
different mitochondrial preparations) and RC was $1.6 \pm 0.2$ (S.D., $n=6$ ). In the presence of BHAM, respiratory rates and coupling parameters were similar $(\mathrm{ADP} / \mathrm{O}=1.40 \pm 0.04, \mathrm{RC}=$ $2.3 \pm 0.3$, S.D., $\mathrm{n}=8$ for mitochondria from low-temperature-grown cells, and $\mathrm{ADP} / \mathrm{O}=$ $1.40 \pm 0.03, \mathrm{RC}=2.4 \pm 0.2$, S.D., $\mathrm{n}=6$ for control mitochondria indicating that BHAM-resistant respiratory activity of the cytochrome pathway was not sensitive to the growth tem-

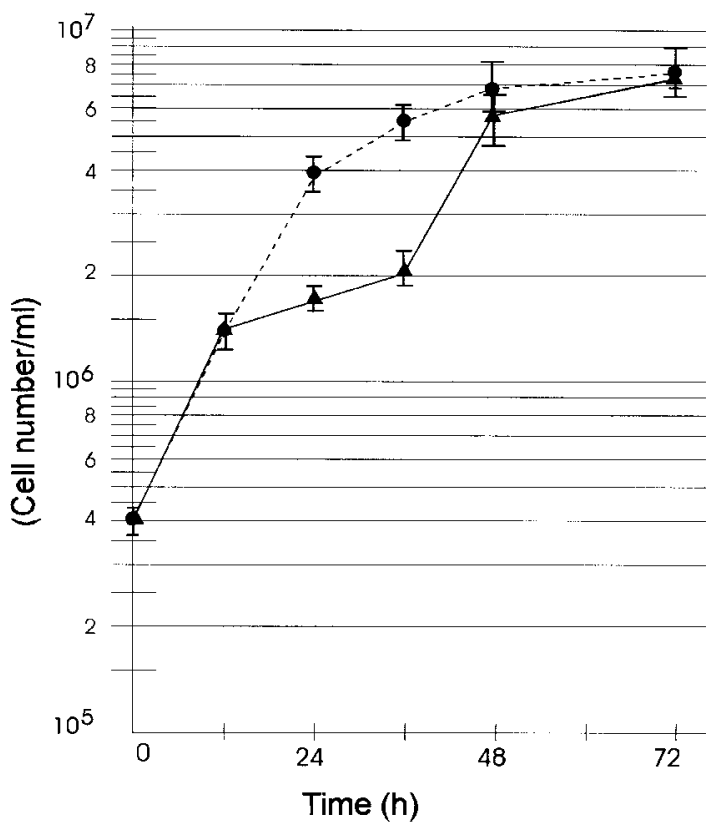

Figure 1. Growth of $A$. castellanii cells in batch culture at $28^{\circ} \mathrm{C}$ and during $24 \mathrm{~h}$ at $6^{\circ} \mathrm{C}$.

Cells from 72 h old cultures were inoculated (time 0) to a final density of approximately $4 \times 10^{5}$ cells $/ \mathrm{ml}$. Control batch culture were grown at $28^{\circ} \mathrm{C}(\bullet$, dashed line). To obtain low-temperature-grown batch culture $(\bullet$, solid line), $12 \mathrm{~h}$ after inoculation amoeba cells were transferred from $28^{\circ} \mathrm{C}$ to $6^{\circ} \mathrm{C}$ for $24 \mathrm{~h}$ and then placed again at $28^{\circ} \mathrm{C}$. To isolate mitochondria amoeba trophozoites were harvested $48 \mathrm{~h}$ after inoculation. Cell numbers were determined at the specified intervals. Mean values ( \pm S.D.) from three separate experiments are shown.

perature of amoeba culture. Thus, the effect of growth temperature on amoeba mitochondrial respiration could not be attributed to an increase in the cytochrome pathway respiration. Furthermore, in the presence of BHAM, there was no difference in state 3 and state 4 membrane potential values measured in mito- chondria from both control and low-temperature-grown amoeba cultures (Fig. 2).

On the other hand, a higher sensitivity of respiratory rates to the AOX inhibitor (BHAM) accompanied by a more significant improvement of coupling parameters were observed in mitochondria from low-temperature-grown cells. This observation could suggest a higher contribution of AOX to total respiration in these mitochondria. The AOX and cytochrome pathway contributions in state 3 respiration can be calculated using the $\mathrm{ADP} / \mathrm{O}$ measurements as described previously [32]. In the example shown in Fig. 2, taking the $\mathrm{ADP} / \mathrm{O}$ ratio without $\mathrm{BHAM}(0.91)$, the contribution of AOX represents $35 \%$, and the contribution of the cytochrome pathway $65 \%$ of state 3 respiration in mitochondria from low-temperature-grown cells. In mitochondria from control cells grown permanently at $28^{\circ} \mathrm{C}$, in which the $\mathrm{ADP} / \mathrm{O}$ value in the absence of BHAM was 1.23 (Fig. 2), the contribution of AOX and cytochrome pathways was $14 \%$ and $86 \%$, respectively.

Thus, it can be concluded that growth of amoeba cells at low temperature led to the increased respiration through the AOX pathway. When malate or external $\mathrm{NADH}$ was used as a respiratory substrate instead of succinate, comparable results were obtained (not shown).

As reported previously by Avery et al. [33], chilling of amoeba cultures (late-exponential and stationary-phase cultures) to $15^{\circ} \mathrm{C}$ resulted in a change in the membrane fatty acid composition (i.e. increased polyunsaturated fatty acid synthesis). However, no change in the fatty acid composition was observed following chilling of early- and mid-exponential-phase cultures. In the present study, when AOX activity was blocked by BHAM, similar respiratory rates and $\mathrm{ADP} / \mathrm{O}$ values and no difference in the value and stability of mitochondrial membrane potential (especially for state 4 respiration) were observed for control cultures and mid-exponential-phase cultures chilled to $6^{\circ} \mathrm{C}$. This indicates that a possible 


\section{C}
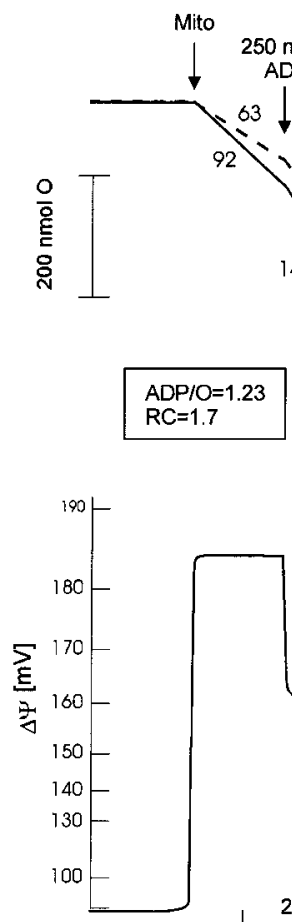

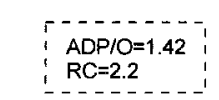

$\mathrm{RC}=2.2$

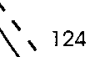

$\because 124$

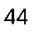

(104)

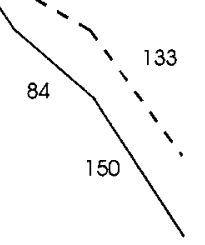

$2 \min \mid$

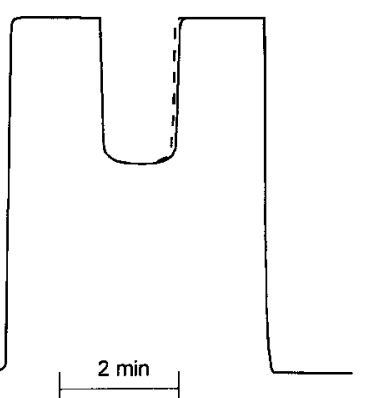

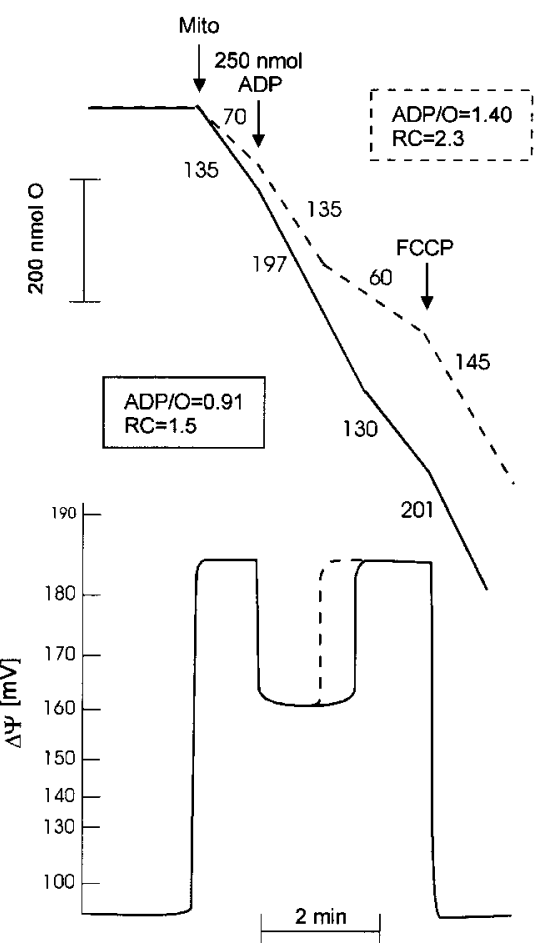

Figure 2. Effect of growth temperature on respiration and coupling parameters in amoeba mitochondria.

Examples of oxygen uptake and $\Delta \Psi$ measurements in mitochondria isolated from control (C) cultures grown at $28^{\circ} \mathrm{C}$ and low-temperature-grown (LTG) cultures. Mitochondria (mito) were incubated in the presence of $10 \mathrm{mM}$ succinate, $0.1 \mathrm{mM}$ ATP, $15 \mu \mathrm{M}$ rotenone, and in the absence (solid lines) or presence (dashed lines) of $1.5 \mathrm{mM}$ BHAM. Additions (where indicated): 250 nmoles ADP, $1 \mu \mathrm{M}$ carbonyl cyanide $p$-trifluoromethoxyphenylhydrazone (FCCP). Numbers at the traces refer to $\mathrm{O}_{2}$ consumption rates in nmol $\mathrm{O} \times \mathrm{min}^{-1}$ per $\mathrm{mg}$ protein. Membrane potential changes are presented in $\mathrm{mV}$. Values of the respiratory control ratio (RC) and ADP/O are shown.

change in fatty acid composition of the inner mitochondrial membrane caused by cold exposure did not lead to increased permeability of this membrane to protons.

\section{Effect of growth temperature on the activity and protein level of amoeba alternative oxidase}

The cyanide-resistant alternative pathwaymediated respiration was higher in mitochondria isolated from low-temperature-grown cells compared to those isolated from control cells. This observation concerns both unstimulated and GMP-stimulated AOX activity (Table 1). The degree of stimulation of cyanide-resistant mitochondrial respiration by GMP was similar for both types of cultures (around 7-fold stimulation), indicating that the increase in AOX activity observed in mitochondria from cells grown at low temperature could be related to the increase in the level of the protein. When antimycin A was used in-

Table 1. Unstimulated and GMP-stimulated cyanide-resistant respiration in amoeba mitochondria from control and low-temperature-grown.

Succinate $(10 \mathrm{mM})$ oxidation was inhibited by $1.5 \mathrm{mM}$ $\mathrm{KCN}$ in the absence or presence of $0.8 \mathrm{mM}$ GMP. Values of $\mathrm{O}_{2}$ uptake are presented in nmol $\mathrm{O} \times \mathrm{min}^{-1}$ per $\mathrm{mg}$ protein. Data are mean values \pm S.D. of three determinations.

\begin{tabular}{lcc}
\hline $\begin{array}{l}\text { Cyanide-resistant } \\
\text { respiration }\end{array}$ & Control & LTG \\
\hline - GMP & $17 \pm 3$ & $30 \pm 7$ \\
+ GMP & $112 \pm 18$ & $210 \pm 24$ \\
\hline
\end{tabular}


stead of cyanide as an inhibitor of the cytochrome pathway respiration, similar results were obtained (not shown).

Immunodetection showed that the amount of $35 \mathrm{kDa}$ AOX protein increased markedly in the mitochondria of amoeba cells grown at $6^{\circ} \mathrm{C}$ as compared with cells grown permanently at $28^{\circ} \mathrm{C}$ (Fig. 3). Thus, in cold-grown

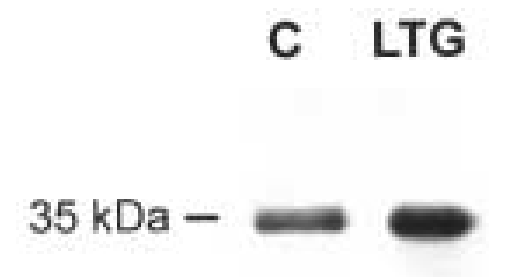

Figure 3. Immunoblots of the alternative oxidase protein in isolated amoeba mitochondria from control (C) cultures grown at $28^{\circ} \mathrm{C}$ and low-temperature-grown (LTG) cultures.

Mitochondrial protein equivalent to $80 \mu \mathrm{g}$ was loaded in both lanes. An example of three immunodetections (using mitochondria from different preparations) is shown. When the total density of $35-\mathrm{kDa}$ bands was measured, a $1.7 \pm 0.2$ (S.D., $n=3$ ) fold increase in the amount of AOX was observed in mitochondria from LTG cultures.

amoeba cells the level of AOX protein in mitochondria was up-regulated (on average, an 1.7fold increase as determined by total density measurements) that could be correlated with the increase in the cyanide-resistant respiratory activity and with a greater electron partitioning to AOX (i.e. increased contribution in total state 3 respiration).

\section{DISCUSSION}

The results presented above clearly indicate that growth of amoeba $A$. castellanii cells at low temperature resulted in increased rates of respiration measured at $25^{\circ} \mathrm{C}$ that can be attributed to a greater activity of the cyanide-resistant pathway, not accompanied by changes in the cytochrome pathway activity. Furthermore, the amoeba cells responded to exposition to a low temperature by an in- crease in AOX protein synthesis which resulted in a higher AOX contribution to total respiration. The effects of chilling on mitochondrial respiration, AOX activity and on up-regulation of AOX protein observed in amoeba mitochondria are similar to those found in some plants exposed to low temperature [17, 23-25, 28].

Free-living soil amoeba $A$. castellanii are relatively tolerant to the low growth temperature [34]. However, their optimal growth temperature is around $28^{\circ} \mathrm{C}$. The question arises what can be the physiological role of up-regulation of AOX protein in response to cold adaptation during the growth of amoeba cells. The cyanide-resistant alternative pathway, the free redox energy-dissipating pathway present in higher plants, some fungi and protozoa, leads to decreased ATP synthesis accompanied by heat production and thermogenesis in some specialized (thremogenic) plant tissues. Since in some plants exposed to chilling temperatures increased heat production was observed, it has been suggested that the alternative pathway could play a local thermoregulatory role [35, 36]. However, the concept of the alternative pathway as "a local thermal balance regulator" that would respond to environmental thermal pressure cannot be extended to unicellular organisms because of their microscopic size that does not allow a local increase in temperature [37]. Moreover, Breidenbach et al. [38] postulated that any temperature increase in plant tissue in which electron flux would be entirely shifted to the AOX pathway would be too small to serve a thermoregulatory role. Therefore, the increased rate of heat production observed after exposure of chilling-sensitive plants to low-temperature [35, 36] must be due to other metabolic factors [28, 38]. Heat production, leading to increase in temperature that results from the activity of AOX, is observed only when total respiration increases tremendously like in specialized plant thermogenic tissues. In non-thermogenic plant tissues and in unicellular organisms heat production by 
energy-dissipating systems may be only a minor side event. In low-temperature-grown amoeba cells, AOX could be considered as response protein to cold exposure (translational regulation) allowing increased oxygen consumption leading to some improvement of biosynthesis and growth at low external temperature. The cost of that improvement would be paid by the free redox energy-dissipation. Amoeba AOX could have a subtle role (more pronounced during chilling) in energy metabolism control working as safety valve when the redox potential or/and phosphate potential become overloaded [37, 39]. Operation of AOX, increased during low temperature exposure, could diminish the rise in reducing power, thus providing $\mathrm{NAD}^{+}$to Krebs cycle and glycolysis and, consequently, carbon skeleton for biosynthesis. Furthermore, similarly as it was previously postulated for plants [28], the increased AOX activity (accompanied by increased protein level) would maintain the rate of the mitochondrial electron transport to oxygen at low temperature, compensating for the higher sensitivity of the cytochrome pathway to cold and thereby preventing production of toxic reactive oxygen species.

\section{R E F E R E N C E S}

1. Hryniewiecka, L., Jenek, J. \& Michejda, J. (1978) Cyanide resistance in soil amoeba Acanthamoeba castellanii; in Plant Mitochondria (Ducet, G. \& Lance, C., eds.) pp. 307-314, Elsevier Science Publishers B.V., Amsterdam.

2. Edwards, S.W. \& Lloyd, D. (1978) Properties of mitochondria isolated from cyanidestimulted and -sensitive cultures of Acanthamoeba castellanii. Biochem. J. 174, 203- 211.

3. Hryniewiecka, L. (1986) Malate oxidation in mitochondria of Acanthamoeba castellanii Neff. Bull. Soc. Sci. Lett. 25, 15-31.

4. Day, D.A., Whelan, J., Millar, A.H., Siedow, J.N. \& Wiskich, J.T. (1995) Regulation of the alternative oxidase in plants and fungi. Aust. J. Plant. Physiol. 22, 497-509.

5. Siedow, J.N. \& Umbach, A.L. (1995) Plant mitochondrial electron transfer and molecular biology. Plant Cell 7, 821-831.

6. Vanlerberghe, G.C. \& McIntosh, L. (1997) Alternative oxidase: From gene to function. Annu. Rev. Plant Physiol. Plant Mol. Biol. 48, 703-734.

7. Sluse, F.E. \& Jarmuszkiewicz, W. (1998) Alternative oxidase in the branched mitochondrial respiratory network: An overview on structure, function, regulation, and role. Braz. J. Med. Biol. Res. 31, 733-747.

8. Jarmuszkiewicz, W., Wagner, A.M., Wagner, M.J. \& Hryniewiecka, L. (1997) Immunological identification of the alternative oxidase of Acanthamoeba castellanii mitochondria. FEBS Lett. 411, 110-114.

9. Edwards, S.W. \& Lloyd, D. (1977) Changes in oxygen uptake rates, enzyme activities, cytochrome amounts and adenine nucleotide pool levels during growth of Acanthamoeba castellanii in batch culture. J. Gen. Microbiol. 102, 135-144.

10. Sharpless, T.K. \& Butov, R.A. (1970) An inducible alternative terminal oxidase in Euglena gracilis mitochondria. J. Biol. Chem. 245, $58-70$.

11. Hanssens, L. \& Verachtert, H. (1976) Adenosine 5'-monophosphate stimulates cyanide-insensitive respiration in mitochondria of Monilella tomentosa. J. Bacteriol. 125, 829-836.

12. Vanderleyden, J., Peeters, C., Verachtert, H. \& Bertrandt, H. (1980) Stimulation of the alternative oxidase of Neurospora crassa by nucleoside phosphates. Biochem J. 188, 141144.

13. Doussiere, J. \& Vignais, P.V. (1984) AMP-dependence of the cyanide-insensitive pathway in the respiratory chain of Paramecium tetraurelia. Biochem. J. 220, 787-794. 
14. Sakajo, S., Minagawa, N. \& Yoshimoto, Y. (1997) Effects of nucleotides on cyanide-resistant respiratory activity in mitochondria isolated from antimycin A-treated yeast Hansenula anomala. Biosci. Biotech. Biochem. 61, 397-399.

15. McIntosh, L. (1994) Molecular biology of the alternative oxidase. Plant Physiol. 105, 781786.

16. Meeuse, B.D.J. (1975) Thermogenic respiration in Aroids. Annu. Rev. Plant Physiol. 26, 117-126.

17. Purvis, A.C. \& Shewfelt, R.L. (1993) Does the alternative pathway ameliorate chilling injury in sensitive plant tissues? Physiol. Plant. 88, $712-718$.

18. Purvis, A.C. (1997) Role of the alternative oxidase in limiting superoxide production by plant mitochondria. Physiol. Plant. 100, 165170.

19. Wagner, A.M. \& Krab, K. (1995) The alternative respiration pathway in plants: Role and regulation. Physiol. Plant. 95, 318-325.

20. Wagner, A.M. \& Moore, A.L. (1997) Structure and function of the plant alternative oxidase: Its role in the oxygen defence mechanism. Biosci. Rep. 17, 319-333.

21. Mackenzie, S. \& McIntosh, L. (1999) Higher plant mitochondria. Plant Cell 11, 571-585.

22. Sluse, F.E. \& Jarmuszkiewicz, W. (2000) Activity and functional interaction of alternative oxidase and uncoupling protein in mitochondria from tomato fruit. Braz. J. Med. Biol. Res. 33, 259-268.

23.Elthon, T.E., Stewart, C.E., McCoy, C.A. \& Bonner, W.D., Jr. (1986) Alternative respiratory path capacity in plant mitochondria: Effect of growth temperature, the electrochemical gradient, and assay pH. Plant Physiol. 80, $378-383$.

24. Stewart, C.R., Martin, B.A., Reding, L. \& Cerwick, S. (1990) Respiration and alternative oxidase in corn seedling tissues during germination at different temperatures. Plant Physiol. 92, 755-760.

25. Vanlerberghe, G.C. \& McIntosh, L. (1992) Lower growth temperature increases alternative pathway capacity and alternative oxidase protein in tobacco. Plant Physiol. 100, 115119.

26. Ito, Y., Saisho, D., Nakazono, M., Tsutsumi, N. \& Hirai, A. (1997) Transcript levels of tandem-arranged alternative oxidase genes in rice are increased by low temperature. Gene 203, 121-129.

27. Atkin, O.K. \& Day, D.A. (1990) A comparison of the respiratory processes and growth rates of selected Australian alpine and related lowland species. Aust. J. Plant Physiol. 17, 517-526.

28. Gonzales-Meler, M.A., Ribas-Carbo, M., Giles, L. \& Siedow, J.N. (1999) The effect of growth and measurement temperature on the activity of the alternative respiratory pathway. Plant Physiol. 120, 765-772.

29.Kamo, N., Muratsugu, M., Hongoh, R., Kobatake, Y. (1979) Membrane potential of mitochondria measured with an electrode sensitive to tetraphenyl phosphonium and relationship between proton electrochemical and phosphorylation potential, in steady state. $J$. Membr. Biol. 49, 105-121.

30. Gornall, A.G., Bardawill, C.J. \& Dawid, M.M. (1949) Determination of serum proteins by means of the biuret reaction. J. Biol. Chem. 177, 751-766.

31. Avery, S.V., Lloyd, D. \& Harwood, J.L. (1994) Changes in membrane fatty acid composition and $\Delta 12$-desaturase activity during growth of Acanthamoeba castellanii in batch culture. J. Euk. Microbiol. 41, 396-401.

32. Jarmuszkiewicz, W., Sluse-Goffart, C.M., Hryniewiecka, L., Michejda, J. \& Sluse, F.E. (1998) Electron partitioning between the two branching quinol-oxidizing pathways in Acan- 
thamoeba castellanii mitochondria during steady-state state 3 respiration. J. Biol. Chem. 273, 10174-10180.

33. Avery, S.V., Harwood, J.L. \& Lloyd, D. (1994) Low-temperature-induced adaptations in fatty acid metabolism of Acanthamoeba castellanii cultures of different ages: Relationship to changes in cell division, oxygen uptake and phagocytotic activity. Microbiol. 140, 24232431.

34. Rodriguez-Zaragoza, S. (1994) Ecology of free-living amoebae. Crit. Rev. Microbiol. 20, 225-241.

35. Ordentlich, A., Linzer, R.A. \& Raskin, I. (1991) Chilling-induced heat evolution in plants. Plant Physiol. 97, 1545-1550.

36. Moynihan, M.R., Ordentlich, A. \& Raskin, I. (1995) Chilling-induced heat evolution in plants. Plant Physiol. 108, 995-999.
37. Jarmuszkiewicz, W., Sluse-Goffart, C.M., Vercesi, A. \& Sluse, F. (2000) Alternative oxidase and uncoupling protein: Thermogenesis versus cell energy balance. Bioscience Reports, in press.

38. Breidenbach, R.W., Saxton, M.J., Hansen, L.D. \& Criddle, R.S. (1997) Heat generation and dissipation in plants. Can the alternative oxidase pathway serve a thermoregulatory role in plant tissues other than specialized organs? Plant Physiol. 114, 1137-1140.

39. Sluse, F.E. \& Jarmuszkiewicz, W. (2000) Activity and functional interaction of alternative oxidase and uncoupling protein in mitochondria from tomato fruit. Braz. J. Med. Biol. Res. 33, 259-268. 